Research Article

\title{
Comparative Study of Nonlinear Static and Time-History Analyses of Typical Korean STS Container Cranes
}

\author{
Quang Huy Tran (D), Jungwon Huh ${ }^{1},{ }^{1}$ Van Bac Nguyen, ${ }^{1}$ Achintya Haldar, \\ Choonghyun Kang, ${ }^{1}$ and Kyeong Min Hwang ${ }^{3}$ \\ ${ }^{1}$ Department of Civil and Environmental Engineering, Chonnam National University, Yeosu 59626, Republic of Korea \\ ${ }^{2}$ Department of Civil Engineering and Engineering Mechanics, University of Arizona, Tucson, AZ 85721, USA \\ ${ }^{3}$ Korea Electric Power Corporation Research Institute, Yuseong-Gu, Republic of Korea
}

Correspondence should be addressed to Jungwon Huh; jwonhuh@chonnam.ac.kr

Received 28 March 2018; Accepted 18 July 2018; Published 16 August 2018

Academic Editor: Tadeh Zirakian

Copyright (c) 2018 Quang Huy Tran et al. This is an open access article distributed under the Creative Commons Attribution License, which permits unrestricted use, distribution, and reproduction in any medium, provided the original work is properly cited.

\begin{abstract}
Ship-to-shore (STS) container gantry cranes, used at terminals for loading and unloading containers from a ship, are an important part of harbor structures. The size and weight of modern STS container cranes are increasing to satisfy the demand for bigger ships. This is expected to result in more lateral load when excited by seismic motions. The existing Korean STS container cranes did not behave properly during several recent moderate earthquakes in South Korea. Typical Korean STS container cranes must be checked for the earthquake-resistant capacity. In this research, two nonlinear static analyses procedures, also known as pushover analyses, commonly used for seismic design of buildings, namely, capacity spectrum method and equivalent linearization method, are comprehensively studied to check their suitability for studying seismic behavior of STS cranes. Results obtained by these two nonlinear static analysis methods are then compared with the results obtained by nonlinear time-history analyses of the STS cranes by exciting them with nine recorded earthquake time histories around worldwide. The behaviors of the cranes are analyzed in terms of the total base shear, drift, and base uplift. The comparisons indicate that the nonlinear static methods can be appropriate for estimating the total base shear and drift of the portal frame of a container crane. The pushover analyses also provide information on performance levels as defined in ASCE/SEI 41-13, of a typical Korean STS container crane. Furthermore, it is observed that the uplift response of the crane is strongly influenced by the duration of an earthquake.
\end{abstract}

\section{Introduction}

Nonlinear static analysis (NSA), also known as pushover analysis (PA), is an effective tool for performance assessment of a structure under a seismic event. It requires less calculation than nonlinear dynamic analysis and avoids using a set of ground motion time histories [1]. As expected, NSA takes a shorter time but is less accurate than the time-history analysis (THA) method since it uses static analysis to capture dynamic effects. The overall steps of the NSA method include the selection of load patterns, nonlinear analysis of the structure to obtain the capacity curve, calculation of displacement demand using a response spectrum, and the assessment of the performance of the structure [1]. There are several NSA methods with the same basic overall schemes, but the detailed steps required to implement them are different. Some of the concepts officially incorporated in design guidelines include capacity spectrum method (CSM) and displacement coefficient method (DCM) as adopted in ATC-40 [2] and ASCE-41 [3], N2 method as proposed in Eurocode 8 [4], and equivalent linearization method (ELM) and displacement modification method (DMM) as presented in FEMA 440 [5]. In addition, several researchers proposed other procedures. They include the adaptive capacity spectrum method (ACSM) by Casarotti and Pinho [6]; the improved capacity spectrum method (ICSM) by Fajfar [7], Lin and Chang [8], and Mingkui et al. [9]; modal pushover analysis (MPA) by Chopra and Goel [10], Freeman [11], Sucuoglu, and Gunay [12]; adaptive modal combinations (AMC) by Kalkan and Kunnath [13]; and the iterative 
displacement coefficient method (IDCM) by Ćosić and Brčić [14]. These methods generally give different results. The definition of the performance point/displacement target and the selection of lateral load patterns used in these methods are the two major reasons for the different results [15]. It is important to note that most of these studies were developed for buildings.

For a special steel structure such as a ship-to-shore (STS) container crane, very different from buildings, as shown in Figure 1, the use of NSA for seismic analyses are expected to be different, with their unique support conditions. In this study, two NSA methods, conventional CSM of ATC-40 and the ELM of FEMA 440, are selected for further consideration. They are selected because they provide a graphical relationship between the capacity of a structure and the seismic demand, and it is relatively easy for engineers to estimate the maximum displacement by using them. In addition, these methods are recommended in many design guidelines and standards worldwide.

The seismic behavior assessment of a typical STS container crane used in South Korea is specifically addressed in this paper. A three-dimensional (3D) finite element (FE) model generated by SAP2000 is analyzed first by CSM and ELM. The results of these NSA methods are then verified by exciting the crane by nine scaled recorded ground motion time histories. The results obtained by CSM and ELM were then compared with the more comprehensive and accurate nonlinear THA. The primary objective of this study is to investigate whether commonly used NSA methods developed for the seismic design of buildings can also be used for a STS container crane. For a comprehensive comparison, the uplift response, base shear, and drift are specifically addressed and compared in this study.

\section{Nonlinear Static and Dynamic Analyses}

2.1. Capacity Spectrum Method (CSM) Procedure. CSM was first proposed by Freeman et al. in 1975 [16] and later introduced in ATC-40 in 1996 [2] and FEMA 274 in 1997 [17]. It is a graphical procedure. This method provides a special treatment for reduction of the seismic demand to intersect the capacity curve in spectral coordinates to find a performance point [2]. An interesting study related to CSM was the AutoCSM method proposed by Guyader and Iwan [18]. AutoCSM is an automated Excel sheet, in which the improved effective linear periods are used to replace the secant period used in the conventional CSM. Essentially, the seismic demand is reshaped by a modification factor. In addition, to improve the accuracy of CSM, Chopra and Goel [19] proposed the use of the constant-ductility inelastic design spectra instead of the elastic damped spectra of the conventional CSM, commonly denoted as ICSM. The procedure is controlled by the ductility factor. Lin and Chang [8] improved ICSM by using the real absolute acceleration response spectrum instead of the pseudoacceleration response spectrum, especially for them system with equivalent viscous damping ratio $\beta_{\mathrm{eq}}>10 \%$ and period $T>0.15 \mathrm{~s}$. Later, Mingkui et al. in 2006 [9] proposed two improvements for the conventional CSM. They considered inelastic demand spectra by using yield strength factor as an elastoplastic index. They also defined and formulated the design acceleration response spectra from the China design building code. Based on the energy equivalent criterion, the equivalent single degree of freedom (SDOF) system was estimated instead of bilinear modeling of pushover curves under the assumption of area equivalence. In 2007, Casarotti and Pinho [6] proposed another procedure, especially for bridge applications, known as ACSM. They constructed an equivalent single-mode capacity curve by combining multimodal pushover response curves. It can be used to study multiple degree of freedom (MDOF) continuous span bridges, considering both flexible and rigid superstructures. Gencturk and Elnashai in 2008 [20] proposed a method for seismic evaluation of woodframe structures. The results showed a significant improvement in the accuracy of CSM as updating the bilinear idealization of the structural system based on the selected trial performance point on the capacity diagram. Recent studies also compared and verified methods proposed by Causevic and Mitrovic [21] and Ferraioli et al. [22]. As discussed previously, the use of NSA for the design of STS crane is very limited. The question remains whether the conventional CSM as suggested in ATC-40 for the design of buildings can also be used for the design of STS containers.

The conventional CSM procedure consists of the following steps as illustrated in Figure 2 [10]:

(1) Construct the pushover curve, which represents the relationship between the base shear $V_{\mathrm{b}}$ and the roof displacement $\Delta_{\text {roof }}$.

(2) Convert the pushover curve to a capacity diagram by transforming $V_{\mathrm{b}}$ to the spectral acceleration $S_{\mathrm{a}}$ and $\Delta_{\text {roof }}$ to the spectral displacement $S_{\mathrm{d}}$ by using the following equations:

$$
\begin{aligned}
& S_{\mathrm{a} i}=\left(\frac{1}{\alpha_{1} W}\right) V_{\mathrm{b} i}, \\
& S_{\mathrm{d} i}=\left(\frac{1}{\Gamma_{1} \phi_{\text {roof } 1}}\right) \Delta_{\text {roof }},
\end{aligned}
$$

where $W$ is the total dead load of the structure and applicable portions of other loads (i.e., service live loads), $\phi_{\text {roof } 1}$ is the amplitude of mode 1 at the roof level, and $\Gamma_{1}$ and $\alpha_{1}$ are the modal participation factor and the modal mass coefficient for the first natural mode, respectively. They can be calculated as follows:

$$
\begin{aligned}
\Gamma_{1} & =\frac{\sum_{i=1}^{N}\left(w_{i} \phi_{i 1}\right) / g}{\sum_{i=1}^{N}\left(w_{i} \phi_{i 1}^{2}\right) / g} \\
\alpha_{1} & =\frac{\left(\sum_{i=1}^{N}\left(w_{i} \phi_{i 1}\right) / g\right)^{2}}{\left(\sum_{i=1}^{N} w_{i} / g\right)\left(\sum_{i=1}^{N}\left(w_{i} \phi_{i 1}^{2}\right) / g\right)} .
\end{aligned}
$$

(3) Convert the elastic response spectrum $\left(S_{\mathrm{a}}\right.$ versus $T$ diagram) to the acceleration-deformation response spectrum format $\left(S_{\mathrm{a}}\right.$ versus $S_{\mathrm{d}}$ format or "ADRS") using the following equation: 


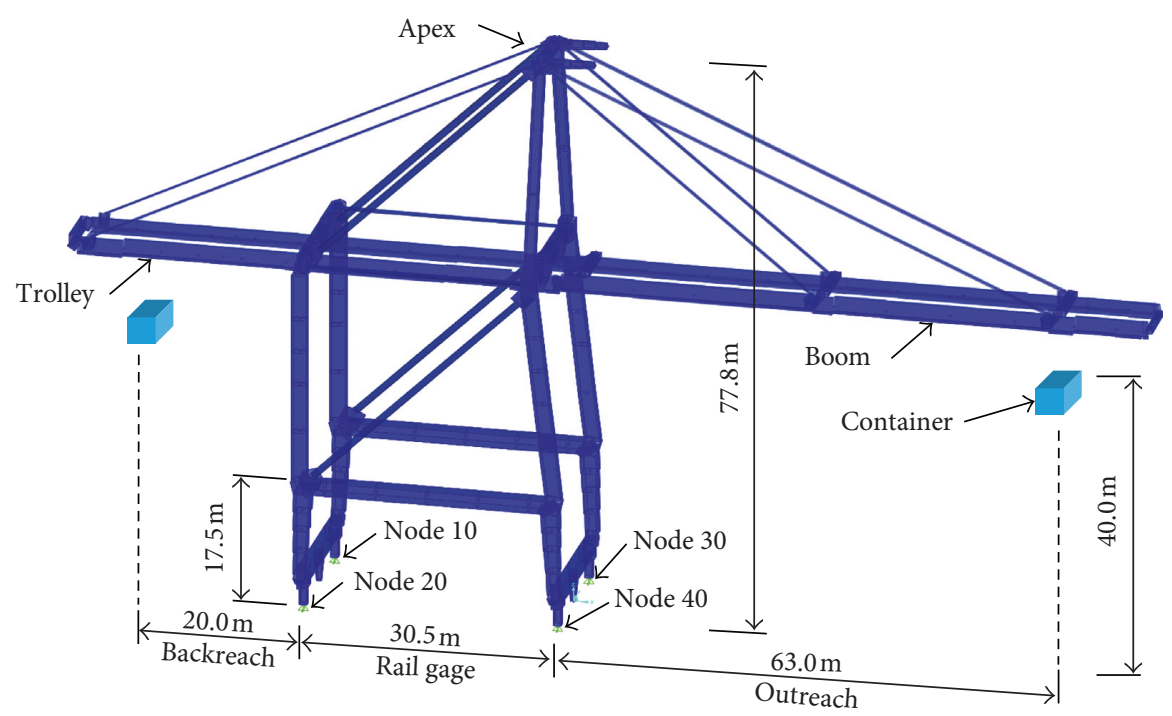

FIgURE 1: 3D numerical FE model of Korea STS container crane.

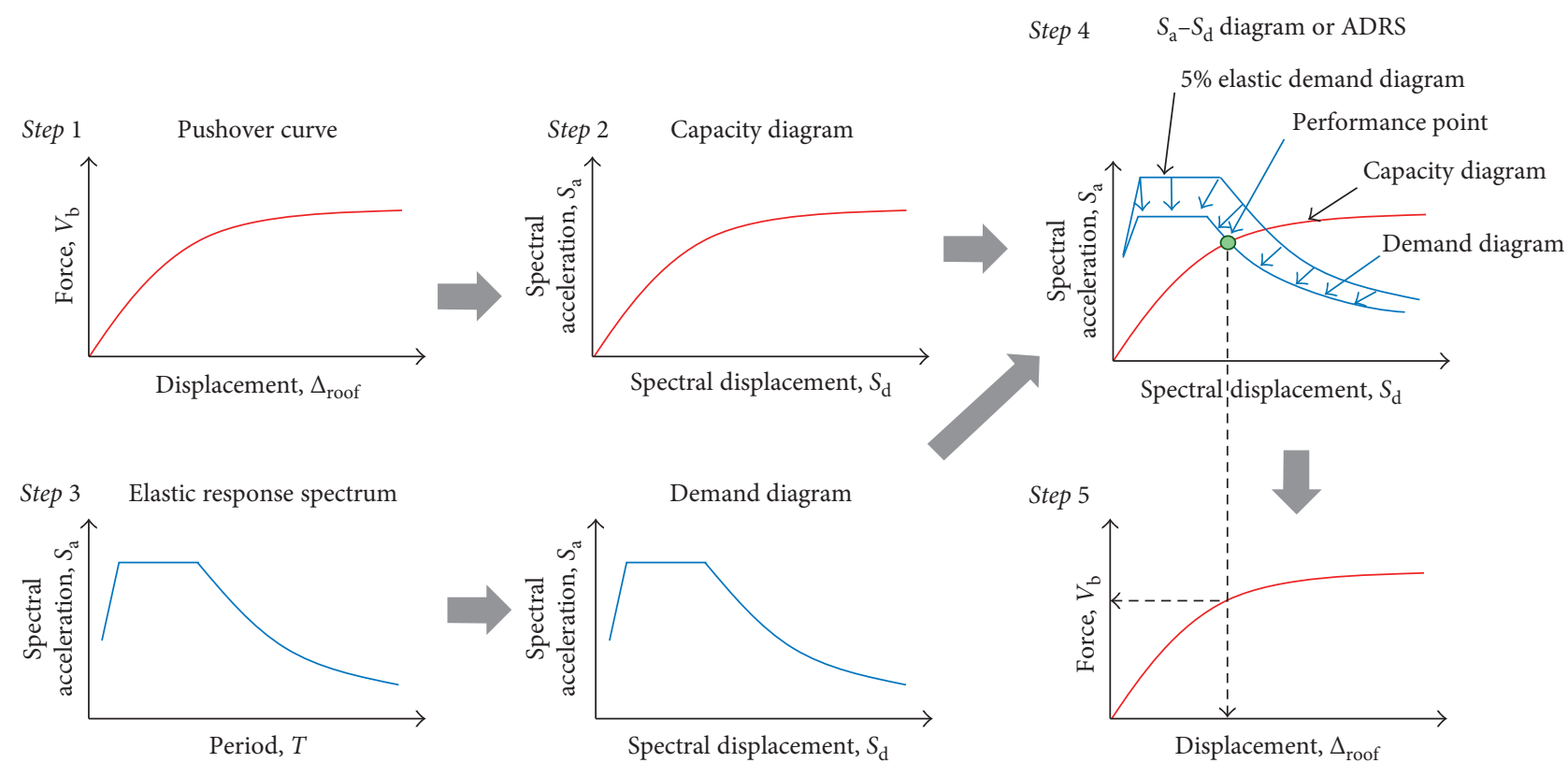

Figure 2: Conventional CSM procedure.

$$
S_{\mathrm{d} i}=\frac{T^{2}}{4 \pi^{2}} S_{\mathrm{a} i} \mathcal{g}
$$

where $T$ is the natural period of the system vibrating within linearly elastic range $\left(u \leq u_{y}\right)$.

(4) Plot the demand and capacity diagrams on the top of each other. Instead of dynamic analyses, a sequence of equivalent linear systems with successively updated values of the natural period of the structure, $T_{\text {eq }}$, and total equivalent viscous damping, $\widehat{\beta}_{\text {eq }}$, provide a basis for estimating the deformation of the inelastic system [10]. The total viscous damping $\widehat{\beta}_{\text {eq }}$ of the equivalent linear system is defined as follows:

$$
\widehat{\beta}_{\mathrm{eq}}=\beta_{0}+\kappa \beta_{\mathrm{eq}},
$$

where $\beta_{0}$ is the viscous damping ratio of a bilinear system for vibrations in linear range $\left(u \leq u_{y}\right), \kappa$ is the adjustment factor depending on structural behavior, and $\beta_{\mathrm{eq}}$ is the equivalent viscous damping ratio as defined in (5). It can also be expressed in detail in (6) for bilinear systems based on Figure 3.

$$
\begin{aligned}
& \beta_{\text {eq }}=\frac{1}{4 \pi} \frac{E_{\mathrm{D}}}{E_{\mathrm{S}}}, \\
& \beta_{\text {eq }}=\frac{2}{\pi} \frac{(\mu-1)(1-\alpha)}{\mu(1+\alpha \mu-\alpha)},
\end{aligned}
$$




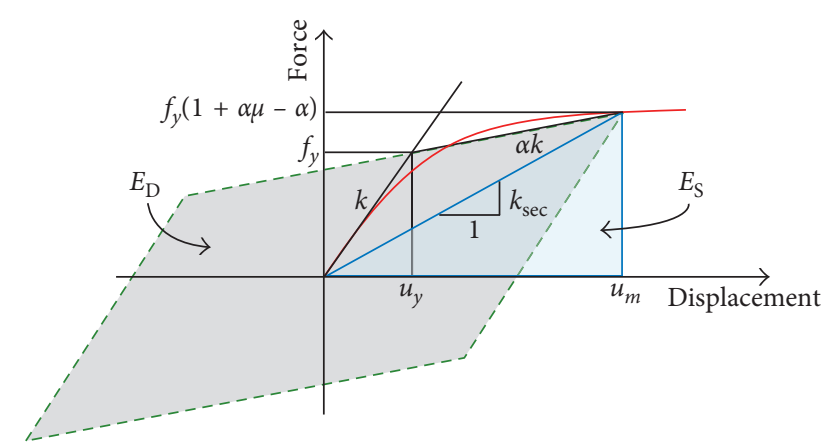

FIGURE 3: SDOF nonlinear system and equivalent viscous damping due to hysteretic energy dissipation.

where $E_{\mathrm{D}}$ and $E_{\mathrm{S}}$ are the energy dissipated in the nonlinear system (area of enclosed by hysteresis loop) and linear system (area of triangle), respectively, $\mu=u_{m} / u_{y}$ is the ductility factor, $\alpha$ is the post-yield stiffness ratio, and $k_{\text {sec }}$ is the secant stiffness. The natural vibration period of the equivalent linear system can be calculated as follows:

$$
T_{\text {eq }}=T \sqrt{\frac{\mu}{1+\alpha \mu-\alpha}} .
$$

(5) Convert $S_{\mathrm{d}}$ from step 4 to $\Delta_{\text {roof }}$ or an individual component deformation and then compare them with the limiting values for the specified performance goals $[10,19]$.

$$
\begin{gathered}
\Delta_{\text {roof }}=S_{\mathrm{d} i} \phi_{\text {roof } 1} \Gamma_{1}, \\
V_{\mathrm{b}}=\alpha_{1} S_{\mathrm{a}} W,
\end{gathered}
$$

where all the parameters in (8) and (9) are already explained in (1) and (2).

\subsection{Equivalent Linearization Method (ELM) Procedure.} Similar to CSM, ELM requires a response spectrum family and uses estimates of ductility to obtain effective period and effective damping. In both procedures, the global deformation demand (including elastic and inelastic) on the structure is computed from the response of an equivalent SDOF system. The difference is in the technique used to obtain the maximum displacement demand [5]. In conventional CSM, the equivalent stiffness of inelastic system is assumed to be the secant stiffness and the equivalent damping is related to the area under the capacity curve as illustrated in Figure 3. In ELM, however, the equivalent stiffness is estimated from effective period $T_{\text {eff }}$ and effective damping $\beta_{\text {eff }}$ derived from statistical analyses, expressed as functions of ductility $\mu$ [5]. $T_{\text {eff }}$ and $\beta_{\text {eff }}$ optimized for application to any capacity curve can be estimated as follows:

For $1.0<\mu<4.0$,

$$
\begin{aligned}
& \beta_{\text {eff }}=4.9(\mu-1)^{2}-1.1(\mu-1)^{3}+\beta_{0}, \\
& T_{\text {eff }}=\left[0.2(\mu-1)^{2}-0.038(\mu-1)^{3}+1\right] T .
\end{aligned}
$$

For $4.0 \leq \mu \leq 6.5$,

$$
\begin{aligned}
& \beta_{\text {eff }}=14+0.32(\mu-1)+\beta_{0}, \\
& T_{\text {eff }}=[0.28+0.13(\mu-1)+1] T .
\end{aligned}
$$

For $\mu>6.5$,

$$
\begin{aligned}
& \beta_{\text {eff }}=19\left[\frac{0.64(\mu-1)-1}{[0.64(\mu-1)]^{2}}\right]\left(\frac{T_{\text {eff }}}{T}\right)^{2}+\beta_{0}, \\
& T_{\text {eff }}=\left[0.89\left(\sqrt{\frac{\mu-1}{1+0.05(\mu-2)}}-1\right)+1\right] T .
\end{aligned}
$$

The above expressions are limited for the initial period of vibration $T$ from 0.2 to $2.0 \mathrm{~s}$ [5]. The effective acceleration $a_{\text {eff }}$ must lie on the capacity curve and coincide with the maximum displacement $d_{\max }$. Thus, the modification factor $M$, defined by (13), is used to adjust the demand spectrum. The modified ADRS (MADRS) procedure is described and depicted in Figure 4 [5].

$$
M=\frac{a_{\mathrm{max}}}{a_{\mathrm{eff}}} .
$$

2.3. Nonlinear Modal Time-History Analysis. To verify the NSA methods, nonlinear modal THA is used in this study. It is also known as fast nonlinear analysis (FNA) in SAP2000. The fundamental equilibrium equation of FNA can be expressed as $[23,24]$

$$
\mathbf{M} \ddot{u}(\mathbf{t})+\mathbf{C} \dot{u}(\mathbf{t})+\mathbf{K u}(\mathbf{t})+\mathbf{R}_{\mathrm{NL}}(\mathbf{t})=\mathbf{R}(\mathbf{t}),
$$

where $\mathbf{M}, \mathbf{C}$, and $\mathbf{K}$ are the mass, proportional viscous damping, and stiffness matrices, respectively, the $\mathbf{R}_{\mathrm{NL}}(\mathbf{t})$ is the nonlinear object force vector from the sum of the forces in the nonlinear elements, and $\mathbf{R}(\mathbf{t})$ is the applied load. At each point of time, the uncoupled modal equations are solved exactly within the elastic structural system, whereas forces within the predefined nonlinear DOF (indexed within $\mathbf{R}_{\mathrm{NL}}(\mathbf{t})$ ) are solved through an iterative process which converges to satisfy equilibrium. In (14), the nonlinear forces are treated as external loads and a set of load-dependent ritz (LDR) vectors, $\Phi$, is generated to accurately capture the effects of those forces.

The input earthquake time histories used in this study consist of nine horizontal ground motions with magnitude ranging from 6.53 to 7.6. All the data were obtained from Pacific Earthquake Engineering Research Center (PEER) [25]. Table 1 shows seven near-fault ground motions (simply assumed with a rupture distance $<15 \mathrm{~km}$ ) and 2 far-fault ground motions.

\section{A Case Study of Numerical Modeling for a Typical Korean STS Container Crane}

3.1. Numerical Simulations. The STS container crane considered in this study is located at a seaport in South Korea. Most of the structural components were made of stiffened hollow box sections, except for diagonal braces, which were tubes, and forestays and backstays, which were wide-flange 


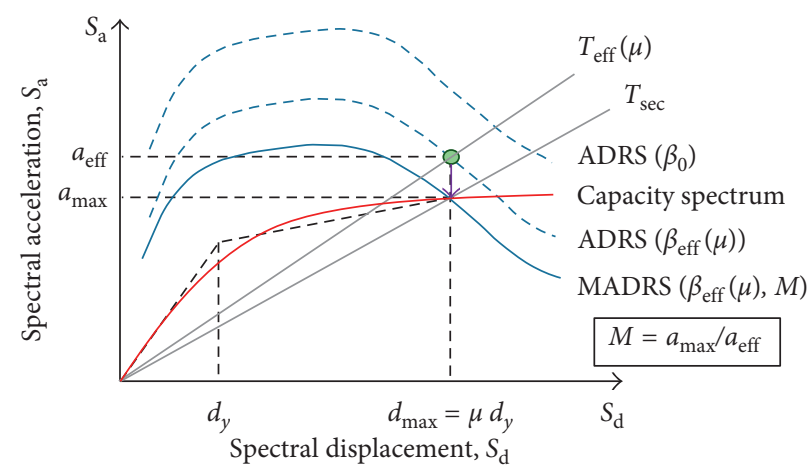

FIGURE 4: Modified acceleration-displacement response spectrum (MADRS).

TABLE 1: Unscaled ground motions recorded during several earthquakes.

\begin{tabular}{|c|c|c|c|c|c|c|c|}
\hline Number (GM) & Earthquake name & Year & Station & Mag. & Mechanism & $R_{\mathrm{RUP}}(\mathrm{km})$ & PGA (g) \\
\hline 1 & Imperial Valley-02 & 1940 & El Centro array \#09 & 6.95 & Strike slip & 6.1 & 0.28 \\
\hline 2 & Imperial Valley-06 & 1979 & El Centro array \#06 & 6.53 & Strike slip & 1.4 & 0.45 \\
\hline 3 & Landers & 1992 & Barstow & 7.28 & Strike slip & 35 & 0.13 \\
\hline 4 & Landers & 1992 & Yermo Fire station & 7.28 & Strike slip & 24 & 0.24 \\
\hline 5 & Loma Prieta & 1989 & Gilroy-Gavilan Coll. & 6.93 & Rev. oblique & 10 & 0.36 \\
\hline 6 & Northridge-01 & 1994 & Newhall-Fire Sta. & 6.69 & Reverse & 5.9 & 0.58 \\
\hline 7 & Northridge-01 & 1994 & Sylmar-Converter Sta. & 6.69 & Reverse & 5.4 & 0.62 \\
\hline 8 & Kobe, Japan & 1995 & KJMA & 6.90 & Strike slip & 1.0 & 0.83 \\
\hline 9 & Chi-Chi, Taiwan & 1999 & TCU065 & 7.62 & Rev. oblique & 0.6 & 0.79 \\
\hline
\end{tabular}

Note. $R_{\mathrm{RUP}}$ is the closest distance to the rupture plane (rupture distance).

shapes. The properties of materials comply with the Japanese industrial standards (JIS) JIS-SM490Y and JIS-STK490. The general dimensions of the crane, that is, outreach, crane gage/span, backreach, and height, are illustrated in Figure 1. A 3D FE model of the container was developed by the SAP2000 software package, as discussed earlier. In the FE representation, the total number of elements is 9916 : 9912 frame elements and 4 gap elements. The forestays, backstays, and diagonal braces were assigned end releases; hence, these elements worked as truss elements. All nonstructural loads, that is, stairs, drive trucks, stowed pins, machinery house, $1 / 2$ festoon, snag device, and boom hoist rope, were applied as concentrated or distributed loads. The modal shapes, natural periods, and frequencies of the first and third mode analyzed by the Ritz vectors method are shown in Figure 5.

3.2. Selection of Seismic Demand. Several boreholes were driven in the area of the seaport to consider the site soil conditions. The soil investigation report showed that the shear wave velocity for the top $30 \mathrm{~m}$ of ground for the five boreholes of the S-PS logging test were from $247 \mathrm{~m} / \mathrm{s}$ to $447 \mathrm{~m} / \mathrm{s}$, as shown in Table 2 . As a result, the soil profile types ranged from $S_{\mathrm{C}}$ to $S_{\mathrm{D}}$ according to Korean Building Code [26], as shown in Table 3. In this study, the soil type $S_{\mathrm{D}}$ was selected. For the crane's site, seismic zone $I$ was considered to be appropriate, and a seismic zone factor $S=0.22 \mathrm{~g}$ was assigned for the maximum considered earthquake (MCE), with a return period of 2400 years. The design acceleration response spectrum of soil type $S_{\mathrm{D}}$ was then developed corresponding to site coefficients $F_{\mathrm{a}}$ (for short period) and $F_{\mathrm{v}}$ (for $1 \mathrm{~s}$ period), of 1.36 and 1.96, respectively. From the 5\% damping elastic response spectrum of soil type $S_{\mathrm{D}}$, as shown in Figure 6 (the red curve), the $S_{\mathrm{a}}$ at the fundamental period (mode 3 with $T=1.35 \mathrm{~s}$ ) is $0.21 \mathrm{~g}$. To verify the results of nonlinear static analyses, the response spectra of nine recorded ground motions, as shown in Table 1 , were then scaled to a spectral acceleration $S_{\mathrm{a}}$ of $0.21 \mathrm{~g}$ at the fundamental period. The scaled response spectra of the recorded ground motions and design response spectrum according to KBC 2016 are shown in Figure 6.

3.3. Nonlinear Static Analysis and Damage Criteria. The plastic hinges were assigned to the portal frame as illustrated in Figure 7 assuming that they develop at the end of the frames using concentrated plasticity model $[23,27]$. The properties of plastic hinges are suggested in ASCE/SEI 41-13 [3]. For portal beams, the moment-curvature $(M-\phi)$ relationship is sufficient to model the hinges assuming no axial force is acting in them. Although interaction relationship of the axial force $(P)$ and the moments $(M)$ in both axes is required for portal columns of a 3D model, a pinned support is used for the pushover analysis to generate large portal deformations during autoincrement static pushing. The limit state obtained by pushover analyses can be applied to THA for a FE model using gap elements because the structural capacity is independent of the loading [28]. According to the structural performance levels and damage defined in ASCE/SEI 41-13 for buildings, the expected performance 


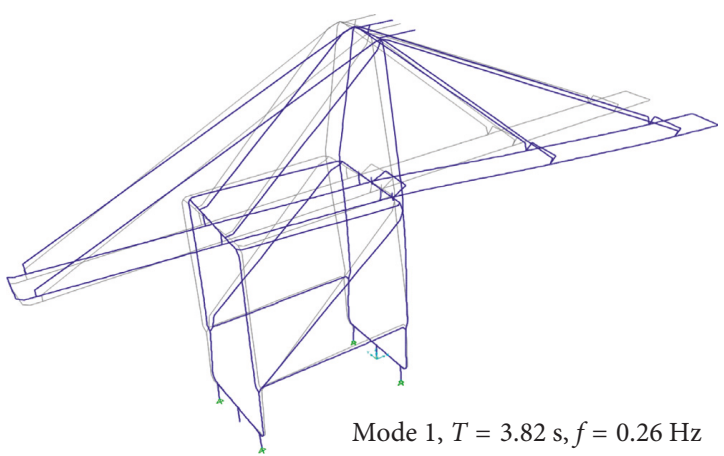

(a)

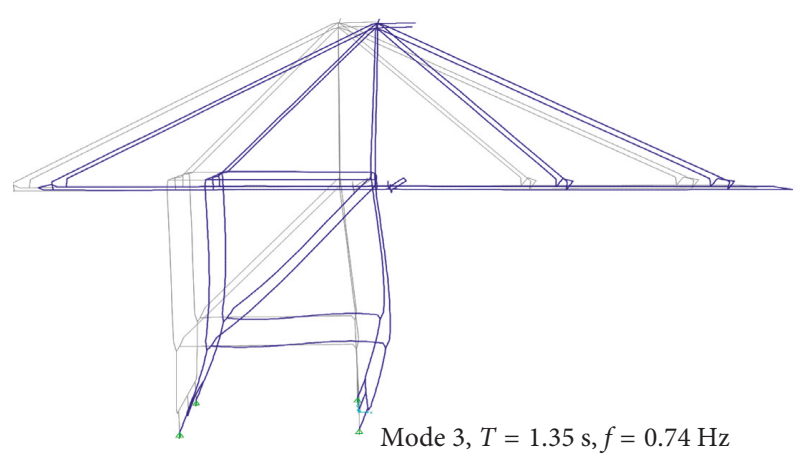

(b)

FigURE 5: Numerical fundamental periods and modal shapes: (a) boom torsion and (b) portal sway.

TABLE 2: Soil investigation at a seaport in South Korea.

\begin{tabular}{lcc}
\hline Boreholes & Shear wave velocity GL. $-30 \mathrm{~m}, v_{\mathrm{s}}(\mathrm{m} / \mathrm{s})$ & Soil types \\
\hline BH-1 & 406 & $S_{\mathrm{C}}$ \\
BH-2 & 252 & $S_{\mathrm{D}}$ \\
BH-3 & 447 & $S_{\mathrm{C}}$ \\
BH-4 & 247 & $S_{\mathrm{D}}$ \\
BH-5 & 337 & $S_{\mathrm{D}}$ \\
\hline
\end{tabular}

levels for steel container cranes (considering as steel moment frame, SMF) are shown in Table 4. In previous studies, derailment, defined as the reduction of the axial reaction of at least one leg base to be zero due to sufficient lateral loads, was considered as a damage state [28]. However, it is reported that a crane was repaired by repositioning it on the rails by jacking systems and mobile crane when it was derailed without any damage to the upper structure, that is, the repair of a Krupp crane at the Port of Oakland in the past in this way [29]. Hence, derailment is assumed to be the only form of the crane's movement without damage of the structure, and the portal frame is still considered to be elastic. Consideration of slight derailment is not considered as a damage state in this study. The damage state considered in this study focuses only on the structural behavior of the portal frame. Several other damage criteria for STS container cranes were suggested in previous studies $[28,30]$, as briefly summarized in Tables 5 and 6 , based on observations of damages of container cranes subjected to past earthquakes, testing of scaled models on shaking table, and analyses of FE models.

For the NSA procedures, a concentrated force was applied at the boom level, as illustrated in Figure 7, under displacement-controlled analyses. The results of pushover analyses indicate that both columns reach the limit states at the same portal drift level even when the concentrated force is applied in the seaward or landward direction. In addition, since the cross sections of the waterside and landside legs are slightly different, they are expected to have similar stiffness and strength. As a result, Figure 7 indicates that both columns reach the immediate occupancy (IO), life safety (LS), and collapse prevention (CP) levels at a portal drift of approximately $1.6 \%, 1.8 \%$, and $2.2 \%$, respectively. In this study, the complex stiffened box sections of the portal columns have been converted into unstiffened box section for simplicity. The section of the top of the portal columns is illustrated in Figure 8 . The $x$-axis and $y$-axis are the trolley-travel direction and gantry-travel direction (along the rails), respectively. It is noted that the hollow box sections at the top of the portal columns of the Korean crane are smaller than those of crane J100, as mentioned in Table 6. Even the overall height of the Korean crane is greater than that of the J100. Past records indicate that there were few moderate to large earthquakes in Korea. Thus, an optimization of the general stiffness of the whole structure of a crane with less emphasis on the seismic effect can reduce the initial cost for the owner.

The ADRS diagrams consisting of both capacity and seismic demand are shown in Figure 9. The CSM and ELM were performed under the seismic demand of KBC 2016 with a selected damping ratio of $1.5 \%$ as suggested by Kosbab for a jumbo container crane [28, 31]. The results from both pushover methods are similar. The performance point of CSM indicates that the total base shear and maximum horizontal displacement at the top of the portal frame are $1691.82 \mathrm{kN}$ and $10.6 \mathrm{~cm}$, respectively. The total base shear and maximum displacement obtained from ELM are $1691.86 \mathrm{kN}$ and $10.6 \mathrm{~cm}$, respectively, with a ductility ratio $\mu=1.0$ and the modification factor $M=1$.

3.4. Dynamic Analyses. For the input ground motions, the effect of vertical excitation is high when the spectral acceleration $S_{\mathrm{a}}$ of the crane (with a natural period of $0.3 \mathrm{~s}$ ) is greater than $0.5 \mathrm{~g}$, as observed in the experimental study by Kosbab For lower $S_{\mathrm{a}}$, the effect of vertical excitation on the portal drift is around $0.1 \%$ [28]. In this study, the vertical ground motions are neglected with the assumption that their amplitudes are attenuated by the effect of quay wall and local site.

The nonlinear modal THA was considered incorporating the $P-\Delta$ effect. The Rayleigh damping, $\beta$, which relates to the mass and stiffness matrix, was calculated by (15) and (16), considering mode 1 (boom torsion) and mode 3 (portal sway) as shown in Figure 5.

$$
\beta=a_{0} \frac{1}{2 \omega_{n}}+a_{1} \frac{\omega_{n}}{2} .
$$


TABLE 3: Site classification of KBC 2016.

\begin{tabular}{|c|c|c|c|c|}
\hline \multirow[b]{2}{*}{ Soil types } & \multirow[b]{2}{*}{ Soil profile name } & \multicolumn{3}{|c|}{ Average properties on the upper $30 \mathrm{~m}$ of the site profile } \\
\hline & & $\begin{array}{c}\text { Shear wave } \\
\text { velocity, } v_{\mathrm{s}}(\mathrm{m} / \mathrm{s})\end{array}$ & $\begin{array}{l}\text { Standard penetration } \\
\text { resistance, } \bar{N}(\text { blows } / 30 \mathrm{~cm})\end{array}$ & $\begin{array}{c}\text { Soil undrained shear } \\
\text { strength, } \bar{s}_{\mathrm{u}}\left(\times 10^{-3} \mathrm{MPa}\right)\end{array}$ \\
\hline$\overline{S_{\mathrm{A}}}$ & Hard rock & $>1500$ & - & - \\
\hline$S_{\mathrm{B}}$ & Rock & 760 to 1500 & - & - \\
\hline$S_{\mathrm{C}}$ & Very dense soil and soft rock & 360 to 760 & $>50$ & $>100$ \\
\hline$S_{\mathrm{D}}$ & Stiff soil & 180 to 360 & 15 to 50 & 50 to 100 \\
\hline$S_{\mathrm{E}}$ & Soft soil & $<180$ & $<15$ & $<50$ \\
\hline
\end{tabular}

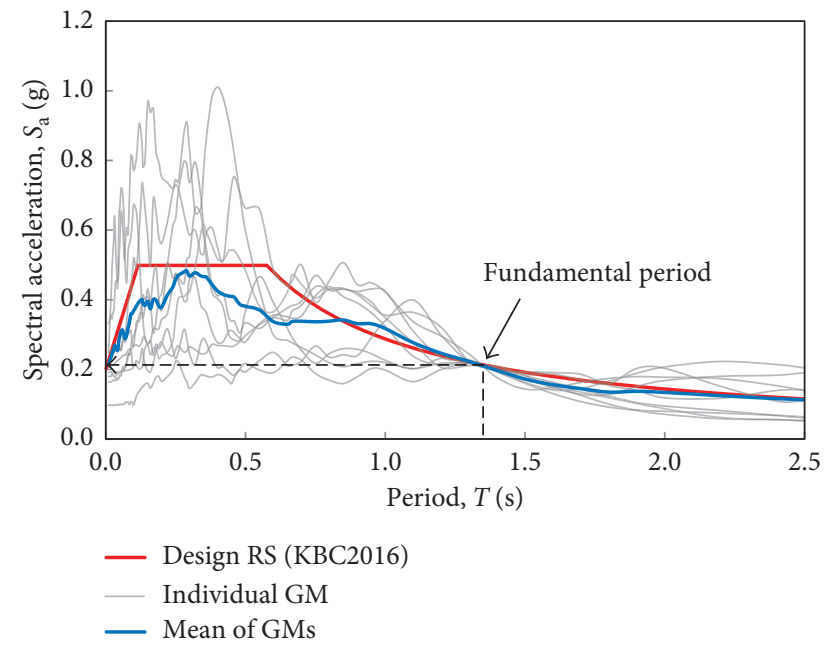

FIgURE 6: Scaled response spectra at the fundamental period.

Assuming that the frequencies of the two modes are $\omega_{i}$ and $\omega_{j}$, having an equal damping ratio of $1.5 \%$, the coefficients $a_{0}$ and $a_{1}$ can be obtained as follows:

$$
\begin{aligned}
& a_{0}=\beta \frac{2 \omega_{i} \omega_{j}}{\omega_{i}+\omega_{j}}, \\
& a_{1}=\beta \frac{2}{\omega_{i}+\omega_{j}} .
\end{aligned}
$$

During the operation, the crane is not fixed to rails or quay wall. For nonlinear THA, therefore, a gap link element is used to simulate the contact between trucks and rails. The gap element is activated when structures come closer and deactivated when they go far away [23]. The axial force will be set to zero when the portal leg is uplifted. The gap element does not disengage in the horizontal direction during uplifting. It is also the limit of this support boundary as discussed in detail by Kosbab [28]. However, a gap element (or a similar type called no tension element) was proven to be suitable to assess the uplift response as proposed by Chaudhuri et al. [32]. The results of the THA together with the NSA methods are discussed in detail in Section 4.

\section{Results and Discussions}

4.1. Drift Response. In contrast to the global drift analysis of a building at the roof level, most of the plastic hinges were

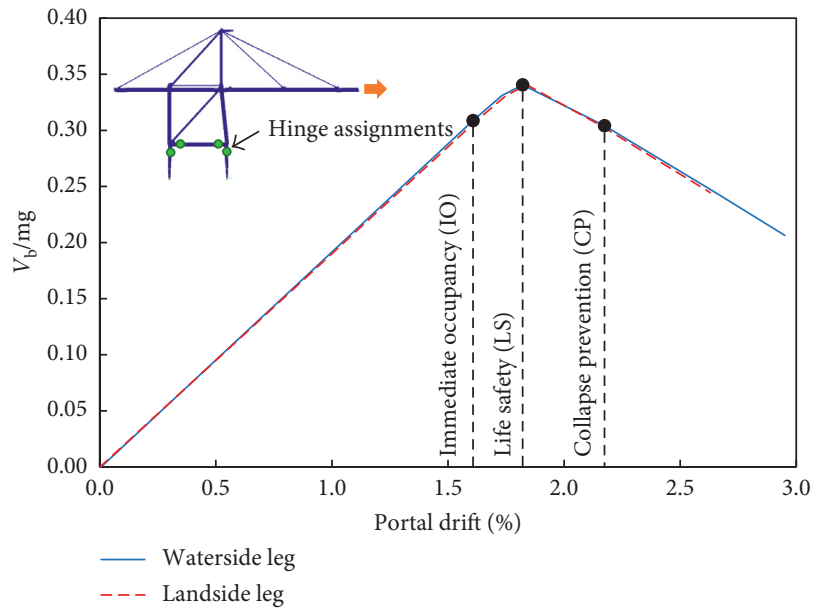

Figure 7: Pushover curve and limit states for typical Korean container crane.

observed to be developed in the portal frame of the crane during past earthquakes. Furthermore, the portal frame is the main structure to support the whole upper structures. Thus, the horizontal displacement or drift at the top of the portal frame is commonly considered $[33,34]$, as shown in Figure 10. The drift at the top of the portal frame (denoted as portal drift) of a container crane provides information on how much of the horizontal deformation occurs at the fundamental mode in the trolley travel direction. Besides measuring the portal drift, the drift at the top of upper legs and apex is monitored along with the corresponding height, as shown in Figure 10. The average drift of the portal frame, top of upper leg, and apex are estimated to be $0.61 \%, 0.26 \%$, and $0.18 \%$, corresponding to heights of $16.6 \mathrm{~m}, 47.1 \mathrm{~m}$, and $76.6 \mathrm{~m}$, respectively, in the trolley travel direction from THA under nine ground motions with scaled PGA ranging from $0.10 \mathrm{~g}$ to $0.32 \mathrm{~g}$. The results of both pushover analyses using CSM and ELM, shown in Figure 9, are in good agreement with that of THA. In particular, the average portal drift of $0.64 \%$ is $0.03 \%$ larger than that of THA. On the other hand, by using the deformation of the fundamental mode, the displacements of the apex obtained from pushover analyses are significantly larger compared to the time-history analyses, with an error of over $16 \%$. The portal drifts obtained from time-history and pushover analyses indicate that the crane behaviors are in the elastic state under seismic excitations, based on the performance levels in Figure 7. According to other performance levels and damage criteria 
TABLE 4: Structural performance levels and damage based on ASCE/SEI 41-13 [3].

\begin{tabular}{lccc}
\hline Elements & Immediate occupancy (IO) & Life safety (LS) & Collapse prevention (CP) \\
\hline $\begin{array}{l}\text { For vertical elements of SMFs (i. } \\
\text { e., portal columns of the crane) }\end{array}$ & $\begin{array}{c}\text { Minor local yielding at a few } \\
\text { places. No fractures. Minor } \\
\text { buckling or observable } \\
\text { permanent distortion of } \\
\text { members. }\end{array}$ & $\begin{array}{c}\text { Hinges form. Local buckling of } \\
\text { some beam elements. Severe } \\
\text { joint distortion but shear } \\
\text { connections remain intact. A few } \\
\text { elements may experience partial }\end{array}$ & $\begin{array}{c}\text { Extensive distortion of beams } \\
\text { and column panels. Many } \\
\text { fractures at moment } \\
\text { connections, but shear } \\
\text { connections remain intact. }\end{array}$ \\
frall damage & Light & fracture. & Moderate
\end{tabular}

TABle 5: Damage criteria for cranes according to PIANC [30].

\begin{tabular}{|c|c|c|c|c|}
\hline Level of damage & Degree I & Degree II & Degree III & Degree IV \\
\hline Displacement & $\begin{array}{l}\text { Without } \\
\text { derailment }\end{array}$ & With derailment & Without overturning & Overturning \\
\hline \multicolumn{5}{|c|}{ Peak response stresses/strains } \\
\hline $\begin{array}{l}\text { (i) Upper } \\
\text { structures }\end{array}$ & Elastic & Elastic & $\begin{array}{c}\text { Plastic }\left(<\mu / \varepsilon_{\max } \text { for upper }\right. \\
\text { structure })\end{array}$ & $\begin{array}{c}\text { Plastic }\left(\geq \mu / \varepsilon_{\max } \text { for upper }\right. \\
\text { structure })\end{array}$ \\
\hline (ii) Portal frame & Elastic & $\begin{array}{c}\text { Plastic }\left(<\mu / \varepsilon_{\max } \text { for portal }\right. \\
\text { frame })\end{array}$ & Without collapse & Collapse \\
\hline (iii) Toe & Elastic & Damage to toe ( & uding pull-out of vehicle, fra & of anchor/brakes) \\
\hline
\end{tabular}

Note. $\mu$ and $\varepsilon_{\max }$ are the ductility factor and strain limit for the structure, respectively.

TABLe 6: Performance levels and limit states proposed by Kosbab [28].

\begin{tabular}{|c|c|c|c|c|}
\hline $\begin{array}{l}\text { Level of } \\
\text { damage/elements }\end{array}$ & Derailment (DR) & Immediate use (IU) & Structural damage (SD) & Complete collapse (CC) \\
\hline Whole structures & $\begin{array}{l}\text { Derailed without any } \\
\text { damage to the structure }\end{array}$ & $\begin{array}{c}\text { Minor structural damage } \\
\text { (not significantly impacts its } \\
\text { operational capacity). } \\
\text { Derailment may or may not } \\
\text { have occurred }\end{array}$ & $\begin{array}{l}\text { Extensive damage and will not } \\
\text { be suitable for use without } \\
\text { major repairs, but not collapse }\end{array}$ & $\begin{array}{c}\text { Local buckling near the } \\
\text { portal joints can quickly } \\
\text { lead to global instability and } \\
\text { eventual collapse }\end{array}$ \\
\hline Portal frame & Elastic & $\begin{array}{l}\text { Lower limit: elastic. High } \\
\text { limit: some minor buckling } \\
\text { of hollow sections (within } \\
\text { the portal frame or not) }\end{array}$ & $\begin{array}{l}\text { A portal } \\
\text { deformation }<\text { deformation at } \\
\text { max. load capacity up to the } \\
\text { point of ultimate ductility }\end{array}$ & $\begin{array}{l}\text { Portal deformation } \\
\text { surpasses the estimated } \\
\text { point of max. ductility }\end{array}$ \\
\hline Overall damage & Derailed & Minor damage & Major damage & Collapse \\
\hline \multicolumn{5}{|c|}{ Limit state in terms of portal drift (for reference) } \\
\hline (i) Crane J100 & $1.3 \%$ & $2.0 \%$ & & \\
\hline (ii) Crane LD100 & - & $1.5 \%$ & $2.0 \%$ & $3.0 \%$ \\
\hline (iii) Crane LD50 & $1.5 \%$ & $1.9 \%$ & $2.5 \%$ & $3.5 \%$ \\
\hline
\end{tabular}

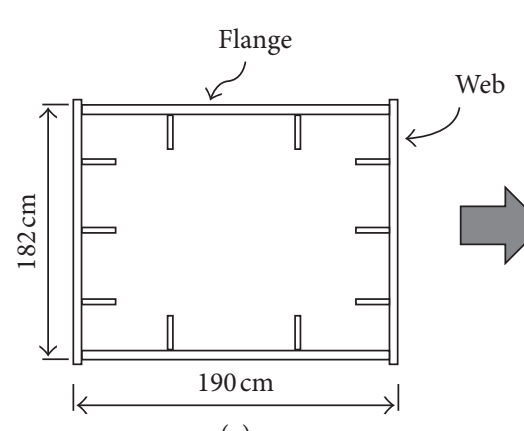

(a)

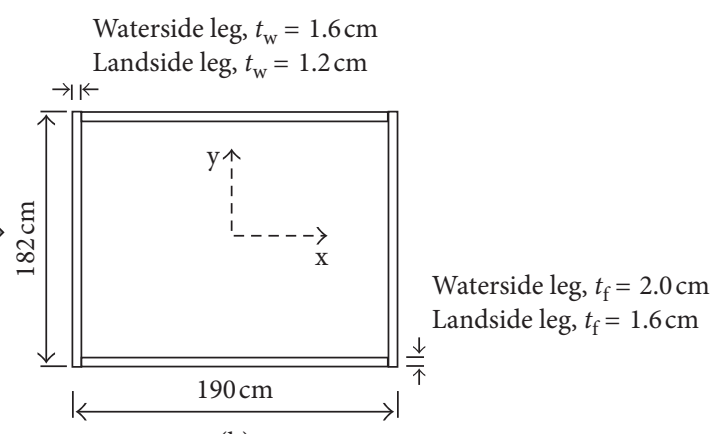

(b)

Figure 8: Hollow box elements: (a) original stiffened section and (b) simplified unstiffened section.

as summarized in Tables 5 and 6, the crane might work in the damage degree $I$ as defined by PIANC and between DR and IU levels according to Kosbab's proposal.
4.2. Total Base Shear. The total base shears obtained from CSM and ELM analyses are plotted in Figure 11. The total base shear is observed to be almost unrelated to the scaled 


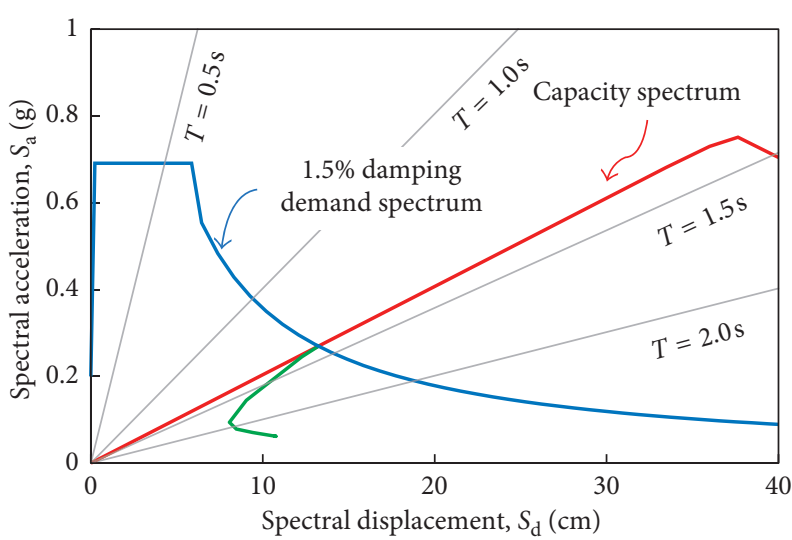

(a)

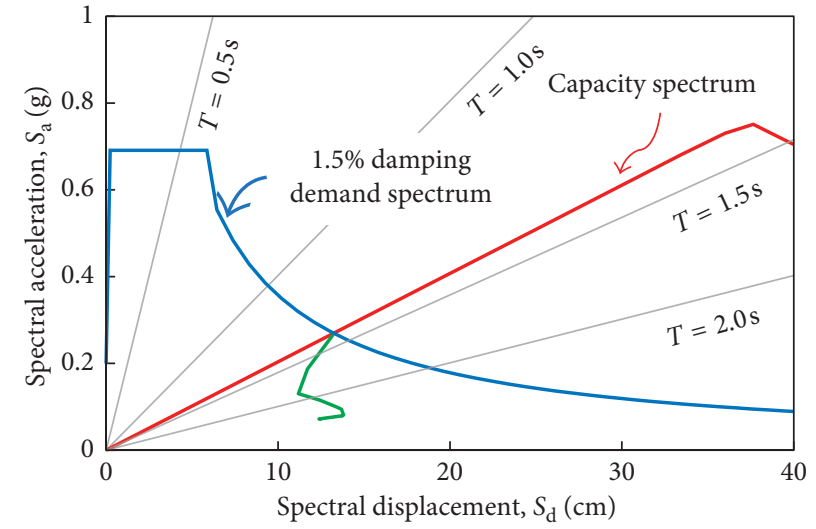

(b)

Figure 9: Pushover analyses: (a) CSM of ATC-40 and (b) ELM of FEMA 440.

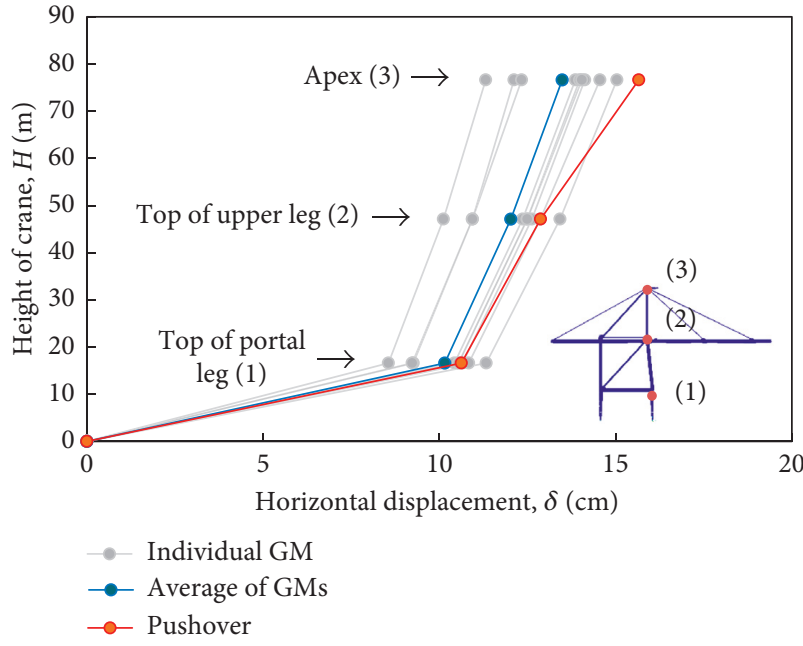

(a)

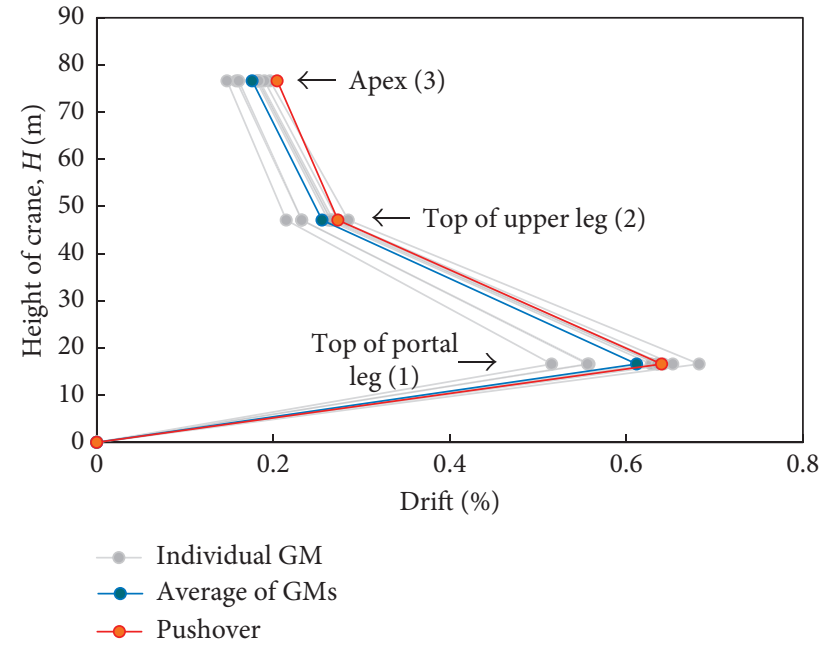

(b)

FIGURE 10: Height of crane versus (a) horizontal displacement and (b) drift.

PGA, magnitude, and rupture distance. For an example, the maximum total base shear is obtained from a minimum PGA ground motion, which is the Landers earthquake at Yermo Fire station in 1992 (GM-4) with a PGA of $0.1 \mathrm{~g}$, or the earthquake with a relatively high PGA value of around $0.24 \mathrm{~g}(\mathrm{GM}-2)$ at a short rupture distance $(1.4 \mathrm{~km})$, generates a lower structural response of $1415.73 \mathrm{kN}$, compared with the average value of $1674.93 \mathrm{kN}$ for the nine ground motion excitations. The total base shears obtained from pushover methods show higher values than the average obtained from THA. In particular, the results for CSM and ELM are $1691.82 \mathrm{kN}$ and $1691.86 \mathrm{kN}$, respectively, as mentioned in the previous section. From this observation, it can be concluded that the pushover methods are suitable for seismic analysis of a STS container crane.

4.3. Uplift Behavior. The uplifting of a crane will result in the redistribution of the load and will change the horizontal displacement of the whole structure. The uplift is defined by two conditions: (1) the vertical displacement of the uplifted leg should be a positive value or zero (a negative value means the gap element is still "close"), and (2) the vertical reaction of the uplifted leg is zero. In this study, four portal legs, two landside legs (node 10 and 20) and two waterside legs (node 30 and 40) as shown in Figure 1, are considered to study uplift responses. Figure 12 shows the potential uplift (in terms of vertical response/displacement) and the time of occurrence of the landside leg (node 20) and waterside leg (node 30). It is noted that the term "potential uplift" is used because the full uplift was not occurred under the earthquake demand as discussed in Section 3.2, just a slight uplift might happen in this study. The full uplift of a crane leg is considered when a leg totally wins against the initial gravity load, which meets both conditions as mentioned above. It can be observed that the potential uplift of landside leg will occur sooner than that of the waterside leg, except for GM-3, GM-8, and GM-9. The reason could be that the center of total 


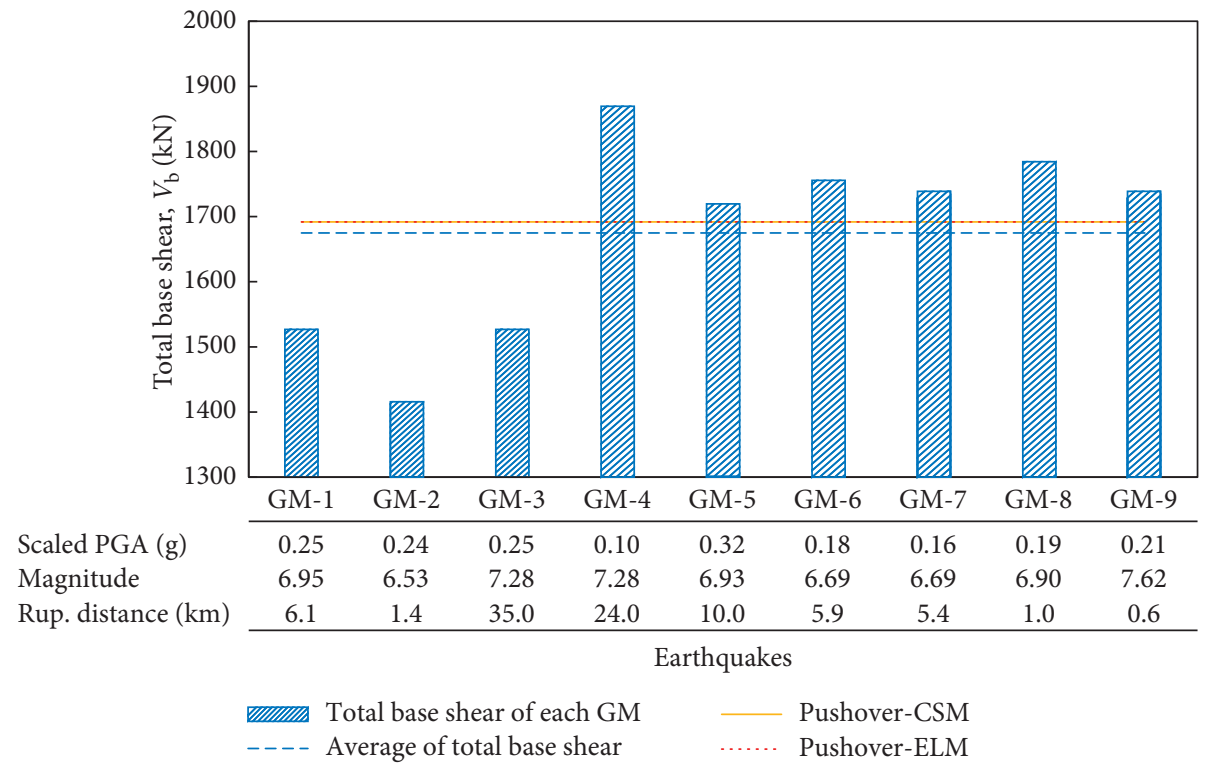

Figure 11: Total base shear versus earthquakes.
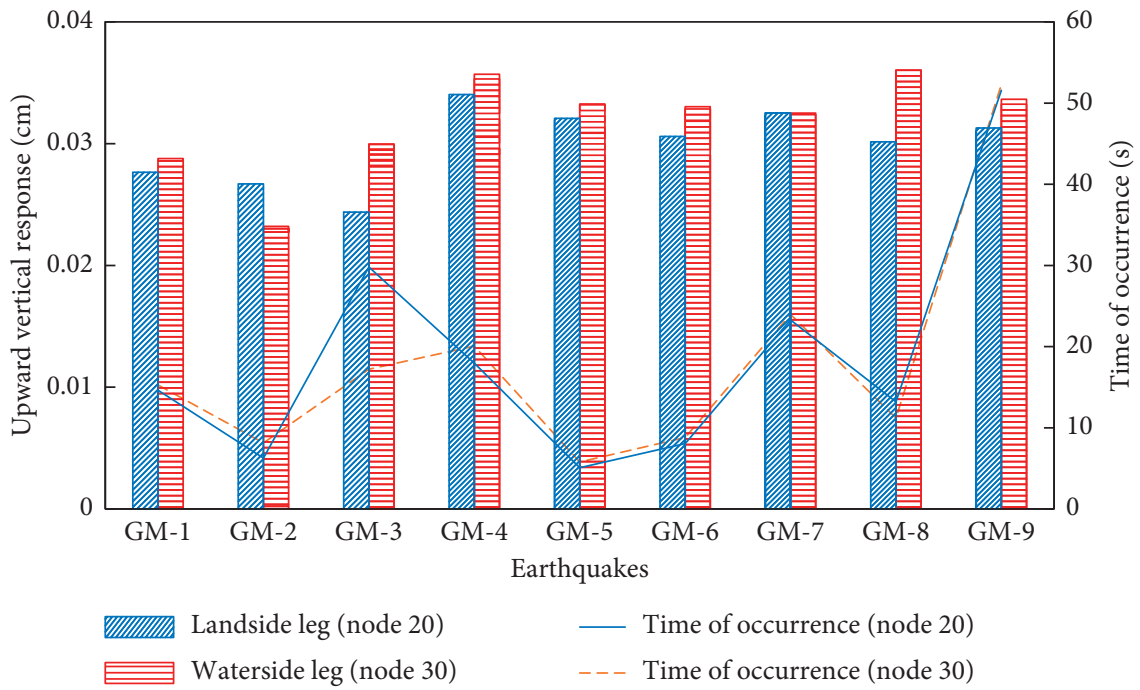

FIGURE 12: Upward vertical responses/displacements of the landside and waterside legs versus time of occurrence due to dynamic analysis (gravity analysis not included).

mass is not at the center of the two portal legs. The total mass concentrates closer to the waterside legs than the landside legs. Thus, the first uplift will occur at the landside legs. When a leg is uplifted, the axial force of the opposite leg will increase significantly. In particular, in this study, it is observed that the maximum axial compressive force increases up to $1204.96 \mathrm{kN}$ on the landside leg (node 10) due to the upward vertical response/displacement of the waterside leg when excited by the Landers earthquake (GM-4) at Yermo Fire station. It is interesting to note that the increase of the axial force of node 10 is approximately $49.5 \%$ compared with the initial gravity force of that node of around $2434.86 \mathrm{kN}$.

On the other hand, the vertical response of crane leg is observed to be strongly influenced by the ground motions' characteristics. Figure 13 indicates that the amplitude of vertical response/displacement decays significantly with time after reaching the peak value when subjected to shortduration earthquakes such as GM-2, GM-5, GM-6, and GM8. However, the vertical response maintains large amplitude for a long time when excited by long-duration earthquakes even when the acceleration amplitude is not as high as in GM-4, GM-7, and GM-9. It can be stated that a longduration earthquake may generate uplift and for a long period of time even when the input ground motion is of low amplitude. Assessment of the uplift behavior is an important issue that should be considered in the seismic design of a container crane to predict the overloading on the portal legs. It is noted that a positive value of the vertical response shown in Figure 13 means that the crane's leg moves upward, whereas a negative value indicates a compression (downward 


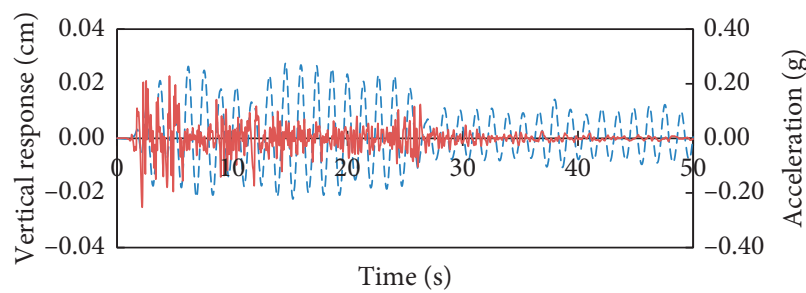

Time (s)

- - Vertical response (landside leg)

— Acceleration (g)

(a)

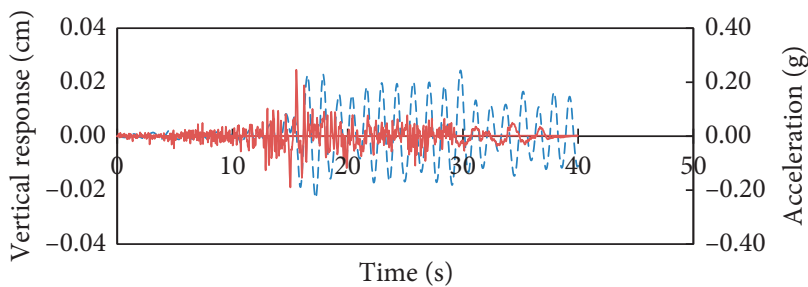

- - Vertical response (landside leg)

_ Acceleration (g)

(c)

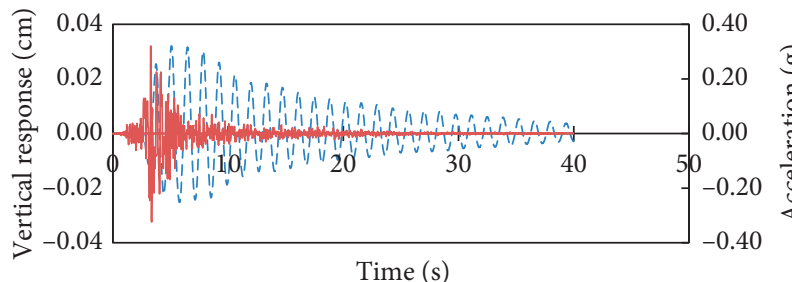

Time (s)

- - Vertical response (landside leg)

— Acceleration (g)

(e)

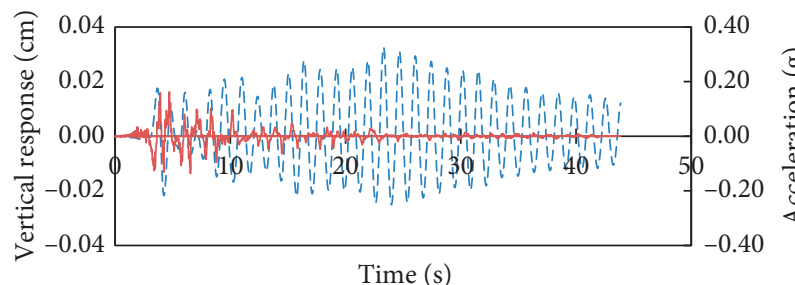

- - Vertical response (landside leg)

— Acceleration $(\mathrm{g})$

(g)

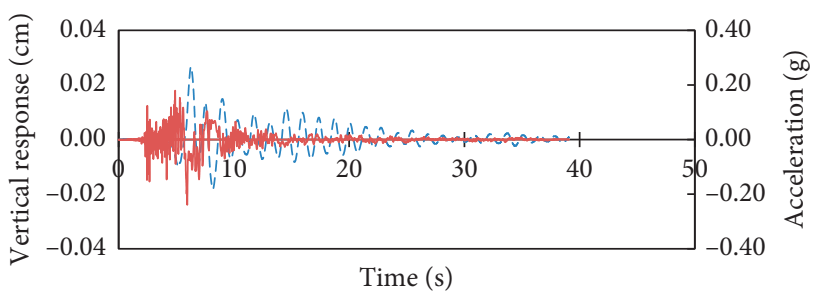

Vertical response (landside leg) Acceleration (g)

(b)

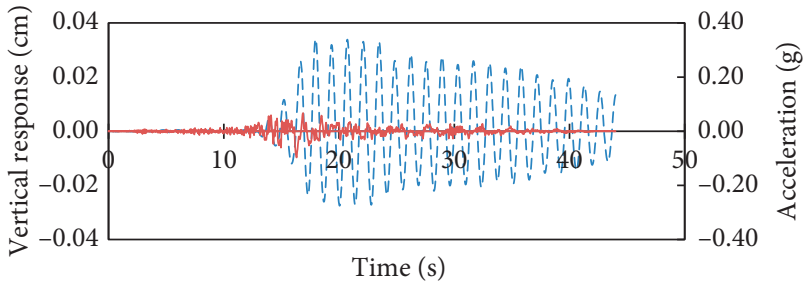

- - Vertical response (landside leg)

— Acceleration (g)

(d)

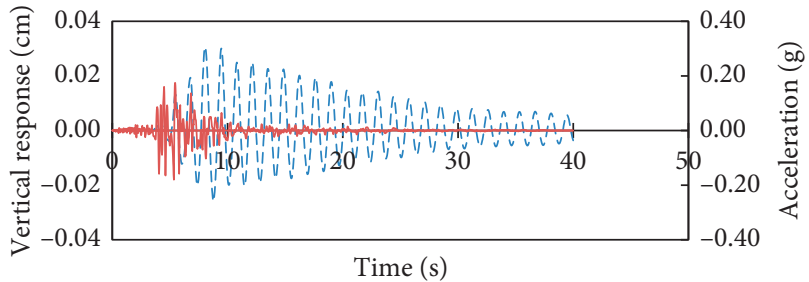

- - Vertical response (landside leg)

- Acceleration (g)

(f)

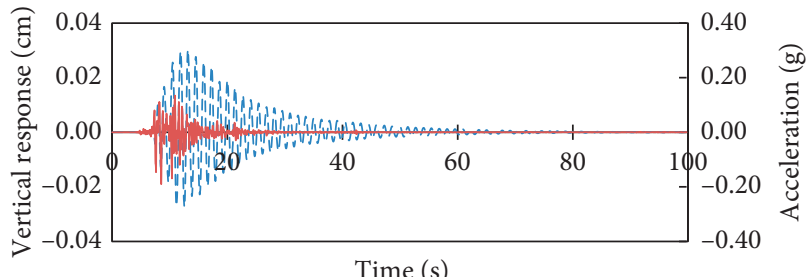

Vertical response (landside leg)

- Acceleration (g)

(h)

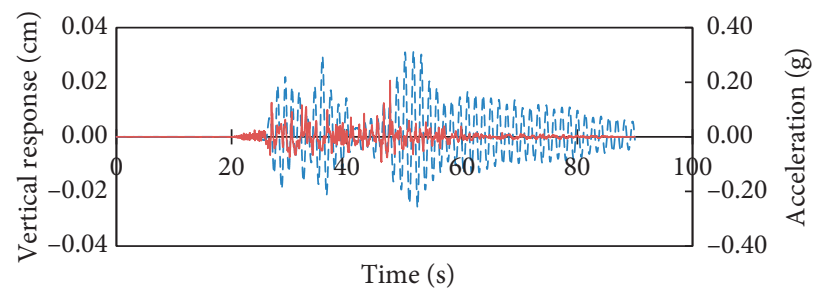

- - Vertical response (landside leg)

— Acceleration (g)

(i)

FIgURE 13: Time-history vertical response of the landside leg (node 20). (a) Imperial Valley-02 (GM-1). (b) Imperial Valley-06 (GM-2). (c) Landers, Barstow (GM-3). (d) Landers, Yermo Fire Station (GM-4). (e) Loma Prieta (GM-5). (f) Northridge-01, Newhall (GM-6). (g) Northridge-01, Sylmar (GM-7). (h) Kobe, Japan (GM-8). (i) Chi-Chi, Taiwan (GM-9). 
movement), comparing with the state after analyzing gravity load. When taking into account both static analysis (gravity load analysis) and dynamic analysis, the value of vertical displacement is still negative in all cases, indicating no full uplift occurrence. For example, under subjected by the earthquake GM-4 (Landers at Yermo fire station), the landside leg (node 20) results in a positive value of $0.034 \mathrm{~cm}$ for dynamic analysis and a negative value of $-0.058 \mathrm{~cm}$ for gravity load analysis; thus, the value considering both cases of analysis is approximately $-0.024 \mathrm{~cm}$ by summation. This means that the crane might be slightly uplifted and will be fully uplifted if the value of displacement reaches zero, and the vertical reaction of the crane leg is zero as well.

\section{Conclusions}

This study represents a preliminary investigation for the seismic behavior of a typical Korean STS container crane. The complex seismic response of the crane is estimated by representing it by a 3D FE model. Nonlinear time-history analysis and both CSM and ELM pushover analyses methods are used to analyze the crane and compare the results. Several key observations can be made based on the results obtained from this study. They are as follows.

The conventional CSM and ELM are found to be sufficient to analyze a STS container crane. In particular, the relative errors of the portal drift and total base shear obtained from pushover methods are $4.6 \%$ and $1.0 \%$, respectively, comparing with those using the nonlinear timehistory analyses. However, the horizontal displacements of the apex of the crane obtained from CSM and ELM appear to be overestimated because these methods consider only the fundamental mode, whereas the nonlinear time-history analysis uses the superposition principle of multiple modes.

Assessment of uplift response is an important issue that should be considered in the seismic analysis of a container crane. It is clearly seen in this study that the axial force of the landside legs increases nearly $50 \%$ of the initial gravity force, as the waterside legs are slightly uplifted. Thus, a gap element, which is integrated into most of the commercial software, is appropriate for modeling base support to study the uplift behavior. On the other hand, the uplift response is strongly influenced by the characteristics of the ground motions. The potential uplift can have large amplitude for a long time when excited by long-duration earthquakes even when the acceleration amplitude may not be high.

The portal drifts of the typical Korean STS container crane corresponding to performance levels of IO, LS, and $\mathrm{CP}$, as defined in ASCE/SEI 41-13, are 1.6\%, 1.8\%, and 2.2\%, respectively. These values can be used as damage limits for the fragility analysis.

\section{Data Availability}

The data used to support the findings of this study are available from the corresponding author upon request.

\section{Conflicts of Interest}

The authors declare no conflict of interest.

\section{Acknowledgments}

This research was supported by Basic Science Research Program through the National Research Foundation of Korea (NRF) funded by the Ministry of Education (2017R1D1A3B03032854) and by Ministry of public Administration and Security as Disaster Prevention Safety Human resource development Project and was also a part of the project titled "Development of performance-based seismic design technologies for advancement in design codes for port structures," funded by the Ministry of Oceans and Fisheries, Korea.

\section{References}

[1] G. H. Powell, Static Pushover Methods-Explanation, Comparison and Implementation, 2013, https://wiki.csiamerica. com/display/perform/Static+pushover+methods+-+explanation $\% 2 \mathrm{C}+$ comparison+and+implementation.

[2] ATC 40, Seismic Evaluation and Retrofit of Concrete Buildings, Applied Technology Council, Redwood, CA, USA, 1996.

[3] ASCE/SEI 41, Seismic Evaluation and Retrofit of Existing Buildings, American Society of Civil Engineers, Reston, VA, USA, 2013.

[4] Eurocode 8, Design of Structures for Earthquake Resistance Part 1: General Rules, Seismic Actions and Rules for Buildings EN 1998, European Committee for Standardization (CEN), Brussels, Belgium, 2004.

[5] FEMA 440, Improvement of Nonlinear Static Seismic Analysis Procedures, Applied Technology Council (ATC-55 Project), Federal Emergency Management Agency, Washington, DC, USA, 2006.

[6] C. Casarotti and R. Pinho, "An adaptive capacity spectrum method for assessment of bridges subjected to earthquake action," Bulletin of Earthquake Engineering, vol. 5, no. 4, pp. 377-390, 2007.

[7] P. Fajfar, "Capacity spectrum method based on inelastic demand spectra," Earthquake Engineering and Structural Dynamics, vol. 28, no. 9, pp. 979-993, 1999.

[8] Y.-Y. Lin and K. Chang, "An improved capacity spectrum method for ATC 40," Earthquake Engineering and Structural Dynamics, vol. 32, no. 13, pp. 2013-2025, 2003.

[9] X. Mingkui, D. Yinfeng, L. Gang, and C. Guangjun, “An improved capacity spectrum method based on inelastic demand spectra," in Proceedings of 4th International Conference on Earthquake Engineering, Taipei, Taiwan, October 2006.

[10] A. Chopra and R. Goel, "Evaluation of NSP to estimate seismic deformation: SDF systems," Journal of Structural Engineering, vol. 126, no. 4, pp. 482-490, 2000.

[11] S. Freeman, "Development and use of capacity spectrum method," in Proceedings of 6th U.S. NCEE Conference on Earthquake Engineering, pp. 1-12, Seattle, WA, USA, June 1998.

[12] H. Sucuoglu and M. S. Gunay, "Generalized force vectors for multi-mode pushover analysis," Earthquake Engineering and Structural Dynamics, vol. 40, no. 1, pp. 55-74, 2011.

[13] E. Kalkan and S. K. Kunnath, "Adaptive modal combination procedure for nonlinear static analysis of building structures," Journal of Structural Engineering, vol. 132, no. 11, pp. 17211731, 2006.

[14] M. Ćosić and S. Brčić, "Iterative displacement coefficient method: mathematical formulation and numerical analyses," Građevinar, vol. 65, no. 3, pp. 199-211, 2013. 
[15] S. Taghavipour, T. Majid, and T. Lau, "Assessment of nonlinear static (pushover) procedures using time-history direct integration analysis," Australian Journal of Basic and Applied Sciences, vol. 7, no. 8, pp. 468-479, 2013.

[16] S. Freeman, J. Nicoletti, and J. Tyrell, "Evaluations of existing buildings for seismic risk-a case study of Puget Sound Naval Shipyard, Bremerton,Washington," in Proceedings of the 1st US National Conference on Earthquake Engineering, Oakland, CA, USA, June 1975.

[17] FEMA 274, NEHRP Commentary on the Guidelines for the Seismic Rehabilitation of Buildings, Federal Emergency Management Agency, Washington, DC, USA, 1997.

[18] A. Guyader and W. Iwan, Automated Capacity Spectrum Method of Analysis, California Institute of Technology, Pasadena, CA, USA, 2004.

[19] A. K. Chopra and R. K. Goel, "Capacity-demand-diagram methods based on inelastic design spectrum," Earthquake Spectra, vol. 15, no. 4, pp. 637-656, 1999.

[20] B. Gencturk and A. S. Elnashai, "Development and application of an advanced capacity spectrum method," Engineering Structures, vol. 30, no. 11, pp. 3345-3354, 2008.

[21] M. Causevic and S. Mitrovic, "Comparison between nonlinear dynamic and static seismic analysis of structures according to European and US provisions," Bulletin of Earthquake Engineering, vol. 9, no. 2, pp. 467-489, 2011.

[22] M. Ferraioli, A. Lavino, and A. Mandara, "An adaptive capacity spectrum method for estimating seismic response of steel moment-resisting frames," International Journal of Earthquake Engineering, Anno XXXIII, Speciale CTA 2015, no. 1-2, pp. 47-60, 2015, http://ingegneriasismica.org/wpcontent/uploads/2016/09/Ferraioli-Nuova-impaginazione.pdf.

[23] SAP2000, Linear and Nonlinear Static and Dynamic Analysis and Design of 3D Structures: Basic Analysis Reference Manual, CSI, Berkeley, CA, USA, 2006.

[24] E. Wilson, Three-Dimensional Static and Dynamic Analysis of Structures: A Physical Approach with Emphasis on Earthquake Engineering, CSI, Berkeley, CA, USA, 2002.

[25] J. Huh, A. Haldar, and S. Yim, "Effect of uncertainty in frequency content and strong motion duration on structural seismic risks," International Journal of Ocean System Engineering, vol. 2, no. 1, pp. 25-37, 2012.

[26] Architectural Institute of Korea, Korean Building Code, Architectural Institute of Korea, Seoul, Republic of Korea, 2016.

[27] J. Huh, Q. H. Tran, A. Haldar, I. Park, and J.-H. Ahn, "Seismic vulnerability assessment of a shallow two-story underground RC box structure," Applied Sciences, vol. 7, no. 7, p. 735, 2017.

[28] B. D Kosbab, Seismic Performance Evaluation of Port Container Cranes Allowed to Uplift, Georgia Institute of Technology, Atlanta, GA, USA, 2010.

[29] Liftech, On the Mend, Liftech Consultants Inc., Oakland, CA, USA, 2008.

[30] PIANC, Seismic Desing Guidelines for Port Structures, A.A. Balkema, Leiden, The Netherlands, 2001.

[31] L. Jacobs, B. Kosbab, R. Leon, and R. DesRoches, "Seismic behavior of a jumbo container crane including uplift," Earthquake Spectra, vol. 27, no. 3, pp. 745-773, 2011.

[32] S. Chaudhuri, D. Karmakar, U. Na, and M. Shinozuka, "Seismic performance evaluation of container cranes," in Proceedings of ATC \& SEI 2009 Conference on Improving the Seismic Performance of Existing Buildings and Other Structures, San Francisco, CA, USA, December 2009.

[33] L. Jacobs, Shake Table Experiments for the Determination of the Seismic Response of Jumbo Container Cranes, Georgia Institute of Technology, Atlanta, GA, USA, 2010.
[34] T. Kanayama and A. Kashiwazaki, "An evaluation of uplifting behavior of container cranes under strong earthquakes," Transactions of the Japan Society of Mechanical Engineers, vol. 64 , no. 618 , pp. 100-106, 1998, in Japanese. 


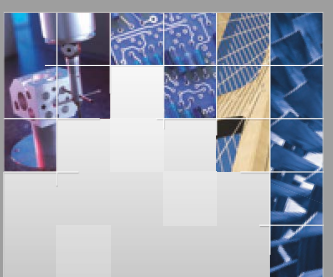

\section{Enfincering}
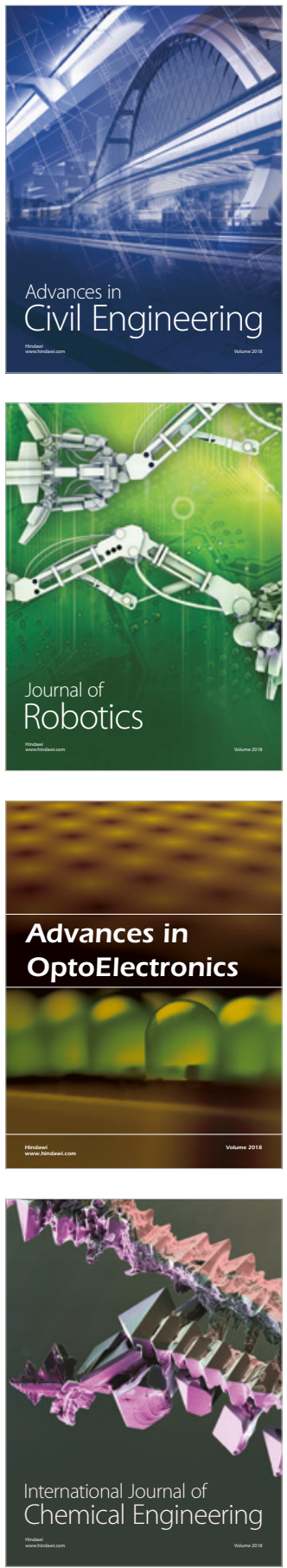

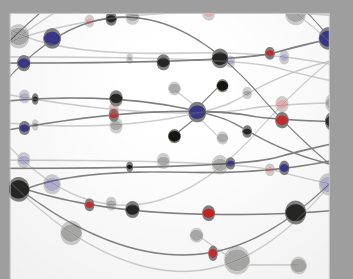

\section{Rotating \\ Machinery}

The Scientific World Journal

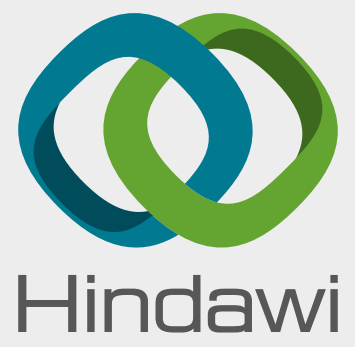

Submit your manuscripts at

www.hindawi.com
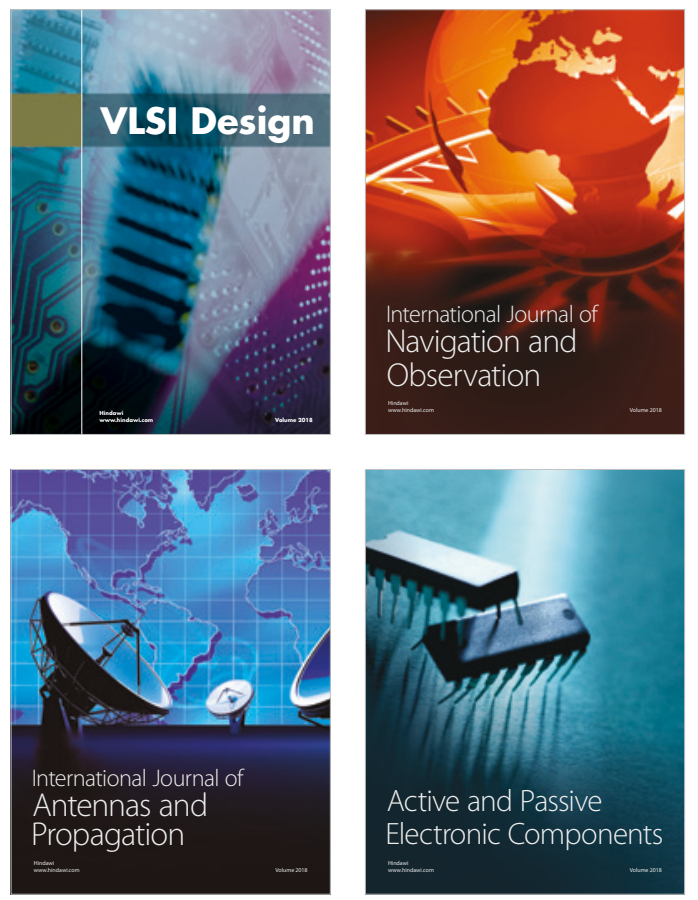
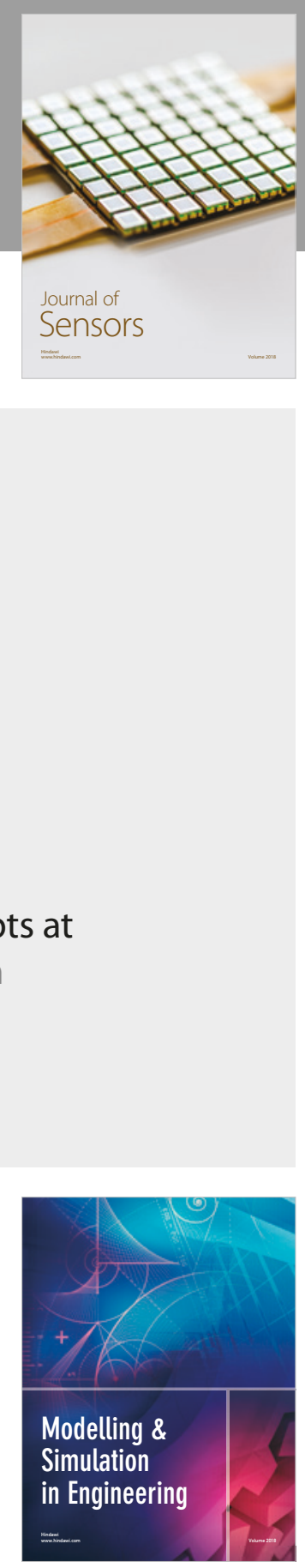

\section{Advances \\ Multimedia}
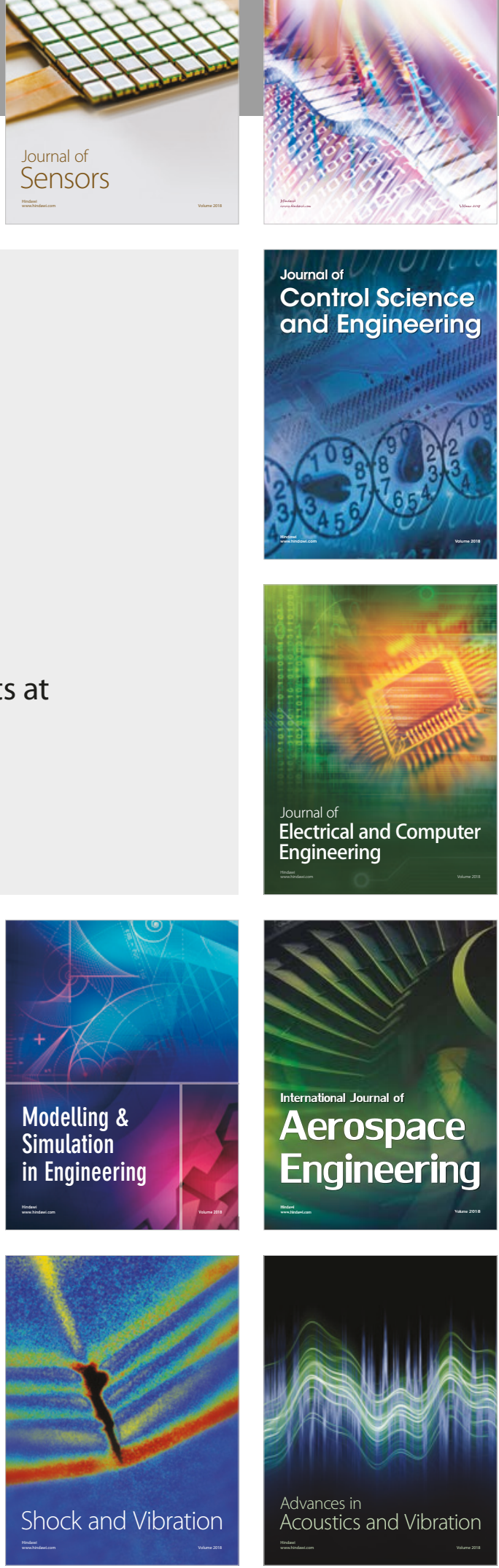